\title{
Correction: USP17 mediates macrophage-promoted inflammation and stemness in lung cancer cells by regulating TRAF2/TRAF3 complex formation
}

\author{
Chih-Hao Lu ${ }^{1,2} \cdot$ Da-Wei Yeh ${ }^{1} \cdot$ Chao-Yang Lai ${ }^{1}$ Yi-Ling Liu ${ }^{1} \cdot$ Li-Rung Huang ${ }^{3}$ Alan Yueh-Luen Lee $\mathbb{C}^{4} \cdot$ \\ S. -L. Catherine $\mathrm{Jin}^{2} \cdot$ Tsung-Hsien Chuang $\mathbb{D}^{1,5}$
}

Published online: 30 May 2019

(c) The Author(s) 2019. This article is published with open access

\section{Correction to: Oncogene (2018) 37:6327-6340 https://doi.org/10.1038/s41388-018-0411-0}

Following the publication of this article, the authors have noticed errors in Fig. 1a, b that were caused due to combined and accidental placement of unrelated data obtained from database search. The authors have corrected these figures. The amended version of Fig. 1 is shown below. Accordingly, the fifth sentence in the first subsection of the Results section is corrected as "Survival analysis of lung cancer data in cBioPortal using an online Kaplan-Meier analysis software revealed that patients with lung cancer exhibiting the top $9.2 \%$ high USP17 expression have a significantly lower survival rate than that of patients with a lower USP17 expression (Fig. 1b)." This correction does not affect the conclusions depicted in Fig. 1a regarding high USP17 expression in lung cancers and those depicted in Fig. $1 \mathrm{~b}$ for the correlation between high USP17 expression and lower survival rate of patients with lung cancer. These conclusions are also supported by other

Tsung-Hsien Chuang

thchuang@nhri.org.tw

1 Immunology Research Center, National Health Research Institutes, Miaoli, Taiwan

2 Department of Life Sciences, National Central University, Zhongli District, Taoyuan City, Taiwan

3 Institute of Molecular and Genomic Medicine, National Health Research Institutes, Miaoli, Taiwan

4 National Institute of Cancer Research, National Health Research Institutes, Miaoli, Taiwan

5 Program in Environmental and Occupational Medicine, Kaohsiung Medical University, Kaohsiung, Taiwan published data [1-3] and our experimental data shown in Fig. 1c, wherein the analysis of USP17 expression in the cDNA array of lung cancers by RT-qPCR demonstrated high expression of USP17 in lung cancers, in particular lung cancers at high stages. The high expression and the pro-tumoral effect of USP17 (DUB3/USP17L2) have also been reported for other tumor types [4-7]. The authors express their sincere apologies for these errors and any inconvenience caused.

Publisher's note: Springer Nature remains neutral with regard to jurisdictional claims in published maps and institutional affiliations.

Open Access This article is licensed under a Creative Commons Attribution 4.0 International License, which permits use, sharing, adaptation, distribution and reproduction in any medium or format, as long as you give appropriate credit to the original author(s) and the source, provide a link to the Creative Commons license, and indicate if changes were made. The images or other third party material in this article are included in the article's Creative Commons license, unless indicated otherwise in a credit line to the material. If material is not included in the article's Creative Commons license and your intended use is not permitted by statutory regulation or exceeds the permitted use, you will need to obtain permission directly from the copyright holder. To view a copy of this license, visit http://creativecommons. org/licenses/by/4.0/.

\section{References}

1. McFarlane C, McFarlane S, Paul I, Arthur K, Scheaff M, Kerr K, et al. The deubiquitinating enzyme USP17 is associated with nonsmall cell lung cancer (NSCLC) recurrence and metastasis. Oncotarget. 2013;4:1836-43.

2. Mehic M, de Sa VK, Hebestreit S, Heldin CH, Heldin P. The deubiquitinating enzymes USP4 and USP17 target hyaluronan synthase 2 and differentially affect its function. Oncogenesis. 2017;6:e348.

3. Hu B, Deng T, Ma H, Liu Y, Feng P, Wei D, et al. Deubiquitinase DUB3 regulates cell cycle progression via stabilizing cyclin A for proliferation of non-small cell lung cancer cells. Cells. 2019;8:297. 
a

\begin{tabular}{|c|l|c|c|}
\hline $\begin{array}{c}\text { Database } \\
\text { accession } \\
\text { number }\end{array}$ & \multicolumn{1}{|c|}{ Data description } & $\begin{array}{c}\text { Fold of } \\
\text { USP17 } \\
\text { induction }\end{array}$ & P-value \\
\hline GSE17599 & $\begin{array}{l}\text { Lung tumor tissues (4) vs. adjacent } \\
\text { normal tissues (4) }\end{array}$ & 2.38 & $3.00 \mathrm{E}-03$ \\
\hline GSE31552 & $\begin{array}{l}\text { Lung tumor tissues (18) vs. } \\
\text { non-tumor tissues (18) }\end{array}$ & 1.22 & $2.87 \mathrm{E}-02$ \\
\hline GSE42127 & $\begin{array}{l}\text { Lung adenocarcinoma tissues stage } \\
\text { 2A(6) vs. Lung adenocarcinoma } \\
\text { tissues stage 1A (32) }\end{array}$ & 1.53 & $9.34 \mathrm{E}-03$ \\
\hline GSE23822 & $\begin{array}{l}\text { Lung squamous cancer tissues } \\
\text { stage 2B (18) vs. Lung squamous } \\
\text { cancer tissues stage 1A (5) }\end{array}$ & 3.06 & $3.40 \mathrm{E}-02$ \\
\hline $\begin{array}{c}\text { GSE66863 } \\
\text { Lung adenocarcinoma tissues stage } \\
\text { 4(2) vs. Lung adenocarcinoma } \\
\text { tissues stage 1A (34) }\end{array}$ & 3.55 & $1.30 \mathrm{E}-02$ \\
\hline $\begin{array}{c}\text { Oncomine } \\
\text { TCGA } \\
\text { Lung2 }\end{array}$ & $\begin{array}{l}\text { Lung mucinous adenocarcinoma } \\
\text { tissues (6) vs. normal lung tissues } \\
\text { (388) }\end{array}$ & 1.203 & $4.40 \mathrm{E}-02$ \\
\hline
\end{tabular}

b

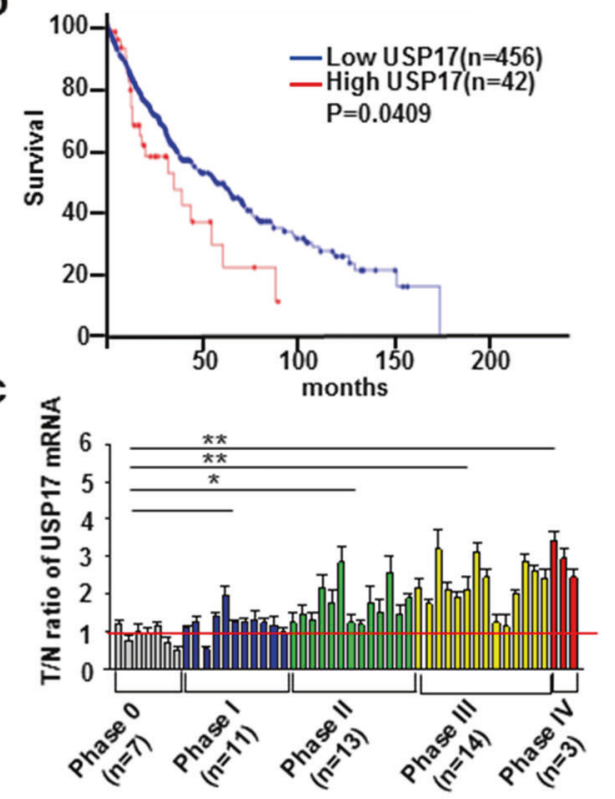

d
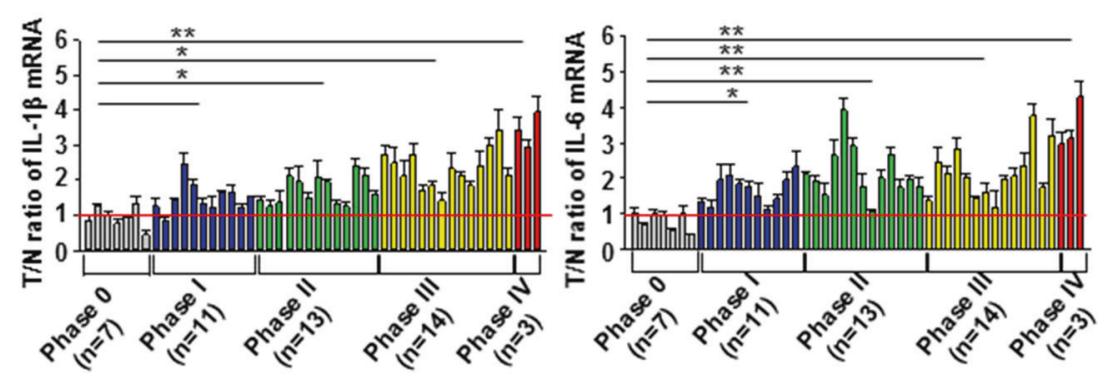

e
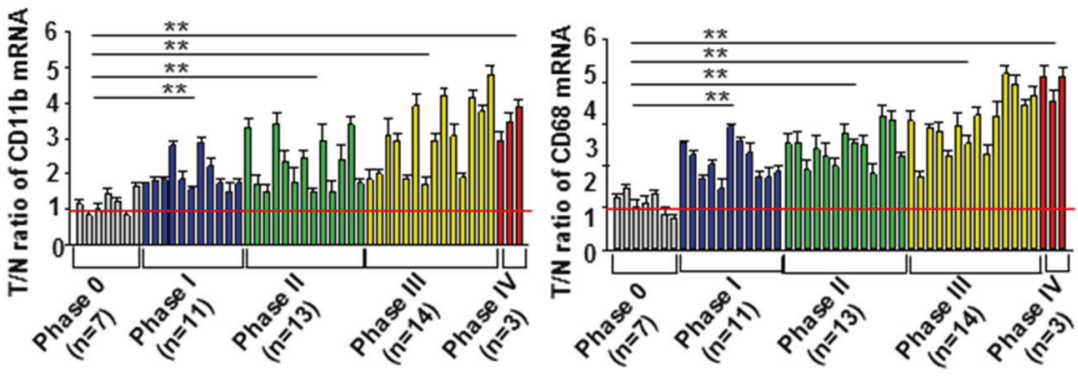

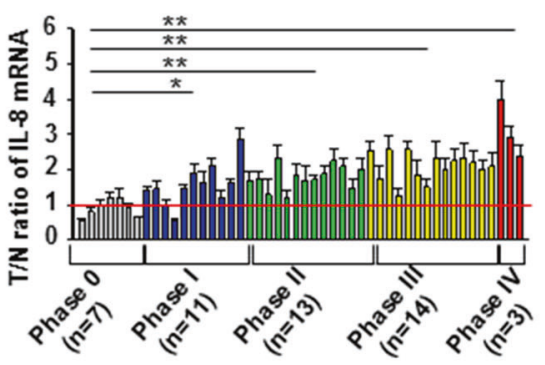

Fig. 1 High expression of ubiquitin-specific peptidase 17, macrophages markers, and inflammatory mediators in lung cancers. a Different GEO and Oncomine datasets as indicated were analyzed for the induction of ubiquitin-specific peptidase 17 (USP17) in tissue samples obtained from patients with lung cancer. b Kaplan-Meier analysis of USP17 expression and survival of patients with lung cancer. Correlation between USP17 expression and survival of patients with lung cancer was analyzed online by the cBioPortal software. The data of

4. Liu T, Yu J, Deng M, Yin Y, Zhang H, Luo K, et al. CDK4/6dependent activation of DUB3 regulates cancer metastasis through SNAIL1. Nat Commun. 2017;8:13923.

5. Wu Y, Wang Y, Lin Y, Liu Y, Wang Y, Jia J, et al. Dub3 inhibition suppresses breast cancer invasion and metastasis by promoting Snail1 degradation. Nat Commun. 2017;8:14228. patients with lung cancer in the database of cBioPortal were from the Cancer Genome Atlas (TCGA). c-d A set of cDNA array prepared from 48 normal or lung cancer tissues was subjected to RT-qPCR for analyzing the expressions of USP17 (c), inflammatory markers (d), and macrophage markers (e) as indicated. Clinic data of each sample are shown in Supplementary Table 1. Data represent mean \pm standard deviation of three analysis, $* P<0.05 ; * * P<0.01$

6. Jin X, Yan Y, Wang D, Ding D, Ma T, Ye Z, et al. DUB3 promotes BET inhibitor resistance and cancer progression by deubiquitinating BRD4. Mol Cell. 2018;71:592-605, e594

7. Wu X, Luo Q, Zhao P, Chang W, Wang Y, Shu T, et al. MGMTactivated DUB3 stabilizes MCL1 and drives chemoresistance in ovarian cancer. Proc Natl Acad Sci USA. 2019;116:2961-6. 